\title{
Shelter for Rohingya Refugees in Bangladesh: A Study about the Crisis and Management of Shelter in the Refugee Camps of Cox's Bazar
}

\author{
Nushrat Tashmin*, Azmery Iqbal Afnan, Abeda Tabassum, \\ Md Kamruzzaman Tusar, S. M. Musfiqur Rahman, Reba Farzana \\ Department of Disaster Science and Management, Faculty of Earth and Environmental Sciences, University of Dhaka, Dhaka, Bangladesh \\ Email: ^nushrat.dsm@du.ac.bd, azmery894@gmail.com, abedaruhee@gmail.com, \\ kamruzzaman.dsm@gmail.com, musfiqur.menon@gmail.com, farzana.reba12@gmail.com
}

How to cite this paper: Tashmin, N., Afnan, A. I., Tabassum, A., Tusar, M. K., Rahman, S. M. M., \& Farzana, R. (2021). Shelter for Rohingya Refugees in Bangladesh: A Study about the Crisis and Management of Shelter in the Refugee Camps of Cox's Bazar. Open Journal of Social Sciences, 9, 262-268. https://doi.org/10.4236/jss.2021.94020

Received: January 31, 2021

Accepted: April 22, 2021

Published: April 25, 2021

Copyright $\odot 2021$ by author(s) and Scientific Research Publishing Inc. This work is licensed under the Creative Commons Attribution International License (CC BY-NC 4.0).

http://creativecommons.org/licenses/by-nc/4.0/

\begin{abstract}
The present study deals with the issue of shelter management of the Rohingya refugees of Bangladesh. The situation of Rohingya inflow has created complex humanitarian emergency in Bangladesh. In this study, the researchers have used different methods to have in-depth insights on the selected issue of shelter management, such as: case study method, key informant interviews and so on. Also researchers have followed the secondary data analysis method to have general insights from different sources on the selected subject area. Without the comprehensive response regarding the shelter management there will be a massive crisis situation for those who are living in refugee camps. Here the aim should be to save lives during the rainy season as they are living in low-lying land of Southern Bangladesh which is bestrewed with rolling hills and susceptible to flash floods and landslides. Moreover the risks of heavy rainfall and cyclone demand immediate action to rescue vulnerable refugees in the camps and the situation requires strengthening vulnerable shelters of the refugee camps to lessen the probability of destructive landslides. Government and Non-Government organizations should play an important role for providing corresponding support to vulnerable refugee households for building and upgrading their shelters which will be resistant in the monsoon season. Also they should promote better and sustainable living conditions in the refugee camps as well.
\end{abstract}

\section{Keywords}

Refugee, Rohingya Refugee, Shelter Management, Shelter Solutions, Humanitarian Emergency 


\section{Introduction}

Bangladesh is now the home of around 1 million Rohingya refugees who ran off from the Rakhine State of Myanmar. They took shelter in Cox's Bazar District of Bangladesh. This fresh influx of the Rohingya is not a first incident. Bangladesh has provided shelters to the flows of Rohingyas since 1978 when the first riot broke out in the Rakhine state in the west of Myanmar, as the Myanmar government consider Rohingya as illegal migrant (Bhattacherjee, 2017). Most of the Rohingya fled to Bangladesh in 1978, 1991-1992, 2012, 2014 and 2016 but flow in 2017 broke the all previous record (Albert, 2018).

The present study deals with the issue of shelter management of the Rohingya refugees of Bangladesh. Over 14000 shelters were built in September, 2018 on 2 thousand acres of land in Cox's Bazar which extended to about 6200 acres. The large and increasing number of the Rohingya influx has created complex humanitarian crisis in Bangladesh which the world has witnessed. In August 2017 due to the ongoing geopolitical crisis Rohingya refugees were forced to flee from Myanmar and arrived in Bangladesh. That time there was little time and budget for the Government of Bangladesh to plan fully settle refugees in the camps with appropriate shelters. However, the speeding flow of the refugees has created the primary crisis of shelter (UN High Commissioner for Refugees, 2018). Government of Bangladesh, UNHCR and other Non-Government Organizations are working on shelter management issue of the Rohingya refugees in southern Bangladesh. Without the comprehensive response regarding the shelter management, there will be a massive crisis situation for those who are living in refugee camps. Here the aim should be to save lives during the rainy season as they are living in low-lying land of Southern Bangladesh which is bestrewed with rolling hills and susceptible to flash floods and landslides. In this study, the researchers have used different methods to have in-depth insights on the selected issue of shelter management, such as: case study method, key informant interviews and so on. Also researchers have followed the secondary data analysis method to have general insights from different sources on the selected subject area. Findings of this study are expected to be useful for academia, government \& nongovernment practitioners and researchers working in the field of refugee studies, humanitarian crisis management other relevant disciplines.

\section{Current Crisis Scenario of Shelter in Refugee Camps}

Since 25 August 2017, an estimated number of 688,000 Rohingya have arrived in Bangladesh. The number is now increasing the total Rohingya population in Cox's Bazar to over 900,000 (International Organization for Migration, 2018). For survival these refugees need basic humanitarian assistance, such as: food, shelter, medical facilities, clean drinking water, and sanitation. Without proper management and comprehensive response, their lives will be endangered. The refugees who have arrived in Bangladesh have already spent most of their money on their way to Bangladesh border and after crossing the border they spent rest 
of their savings for constructing shelters with nothing more than bamboo and thin plastic sheets. The Rohingya populations in Cox's Bazar refugee camps are living are highly vulnerable, as they have faced life threats which have pushed them to flee from their own country. These threats and difficulties during their journey to arrive in a new country as refugees have already created severe mental trauma. Moreover the struggling living conditions in the refugee camps have made them more vulnerable.

Role of Different Organizations: UNHCR and IOM along with BRAC, UNICEF and Save the Children are mainly working to provide shelter kits or tents in the refugee camps. Most of the camps are unplanned which cover over 3,000 acres. Most of the areas are hillsides where the Rohingya are living could collapse due to rain in the monsoon season. The camps are situated in the areas which are at high risk of landslides. Besides, refugees have stripped almost all the vegetation and ripped out tree roots to use as fuel. Experts of UNHCR say that, one of the basic challenges are to provide basic sanitation to a population (Beaubien, 2018). The camp areas will be slippery and muddy during monsoon and it will be near impossible for the development worker to go inside the camp with necessary supports for the refugees (Image 1).

Shelter Conditions of Rohingya Camps: Prior to August 2017, 99 percent of shelters in refugee camps were made with bamboo and thin plastic sheets. These materials are highly vulnerable in the context of natural disasters. But those refugees who are new in the camps have built bamboo structures and covered those with locally available plastic sheets. Some of them have been through debts for securing their families with minimum standard shelters. This situation made them more vulnerable to exploitation during the first weeks after late August. That time, there were budget limitations and the absence of proper planning to build sustainable construction of dwellings for the Rohingya flows. So the locally

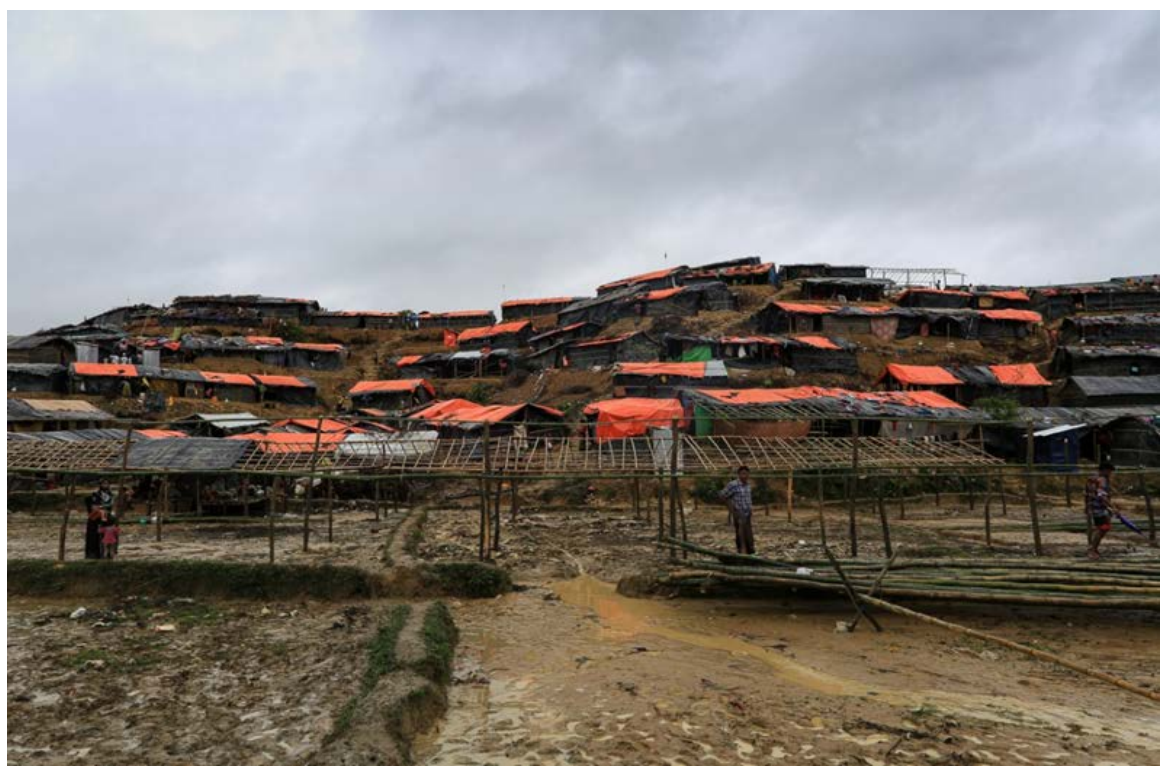

Image 1. Rohingya Camp, Source: (Al Jazeera, 2017). 
available budget specific bamboos and plastic sheets were procured as relief elements to provide basic shelters.

UNHCR provided shelter kits that include foot bamboo poles (which serve as load bearing pillars as well as thinner pieces of bamboos), tarps and tool kits that include hammers, nails and plastic ties for making the shelters waterproof against the monsoon rains. One of the main problems in the refugee camps is the unsafe condition latrines as there is the absence of gender-segregated latrines. Till now, UNHCR has distributed 30,000 shelter kits and fulfilled the target of 80,000 by the end of March 2018 (UN High Commissioner for Refugees, 2018). But the types of tents that are being used in different refugee camps of Cox's Bazar do not appear to be suitable for the region's climate (Image 2).

Crisis due to Monsoon and Natural Disasters: Shelter management situation at the current scenario is moderate considering the number of refugees but will be difficult to manage if more refugees come and join the current population. One of the main problems that the country will be facing is the upcoming heavy precipitation during the Monsoon season as they are residing in the coastal region of the country. They are living in low-lying land of Southern Bangladesh bestrewed with rolling hills, which is susceptible to landslides and flash floods. Another issue is regarding land excavation and clearing of forests to provide acres of land to these refugees. This is not only threating the biodiversity but also this will lead a long-term change in ecology and this rapid change will initiate frequent landslides in near future (Image 3).

\section{What Can Be Done?: Towards Possible Shelter Solutions in Rohingya Refugee Camps}

- Improved building materials and construction should be done to improve the existing camps in Cox's Bazar district of Bangladesh. As the refugee count is

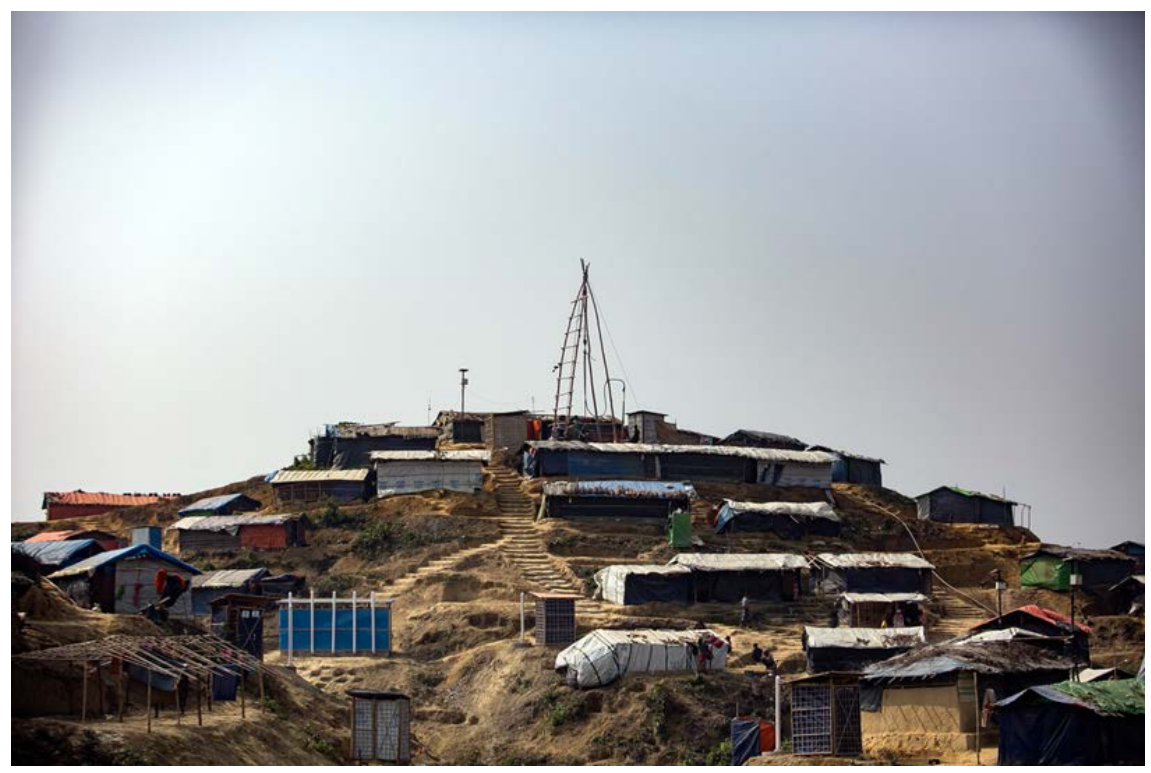

Image 2. Hill in the Kutupalong camp, Source: (Beaubien, 2018). 
over a million now hence larger accommodation capacity should be made per tent. Also, better construction mechanisms should be implied. Along with this ecofriendly roofs and solar panels should be encouraged in the refugee camps. For the provision of shelter solutions, technical guidance is urgently required so that Rohingya populations can live under safer shelters. Appropriate shelter management plan can make local site improvements with proper drainage, fire mitigation and terracing facilities.

- Female-headed households and households with aged and disable persons should be prioritized in the management planning of shelter support. Families with less capacity are more vulnerable and should be supported in their construction and maintenance of shelters. In the construction of shelters, partitions for privacy should be a priory. Adequate access to proper management and maintenance of shelters is also essential.

- Government should provide support and direct guidance towards shelter management, especially during the upcoming monsoon and cyclone seasons. It should include the distribution of bamboo poles, tarpaulins tie-wires, ropes and sandbags.

- As the climate of the camp locations is susceptible to heavy rains and cyclones so it's high time to strengthen the shelters of the camps to prevent the risks of deadly disasters, such as: landslides. Government and Non-Government organizations should promote adequate support to make the shelters sustainable in the contexts of environmental hazards especially during the monsoon season for better and safer living (Martin, 2017).

- There is an urgent need of advocacy in this regard. Also the vulnerable households need further helps in establishing the sustainable shelters. They also require additional support for digging drainage channels and evacuation of

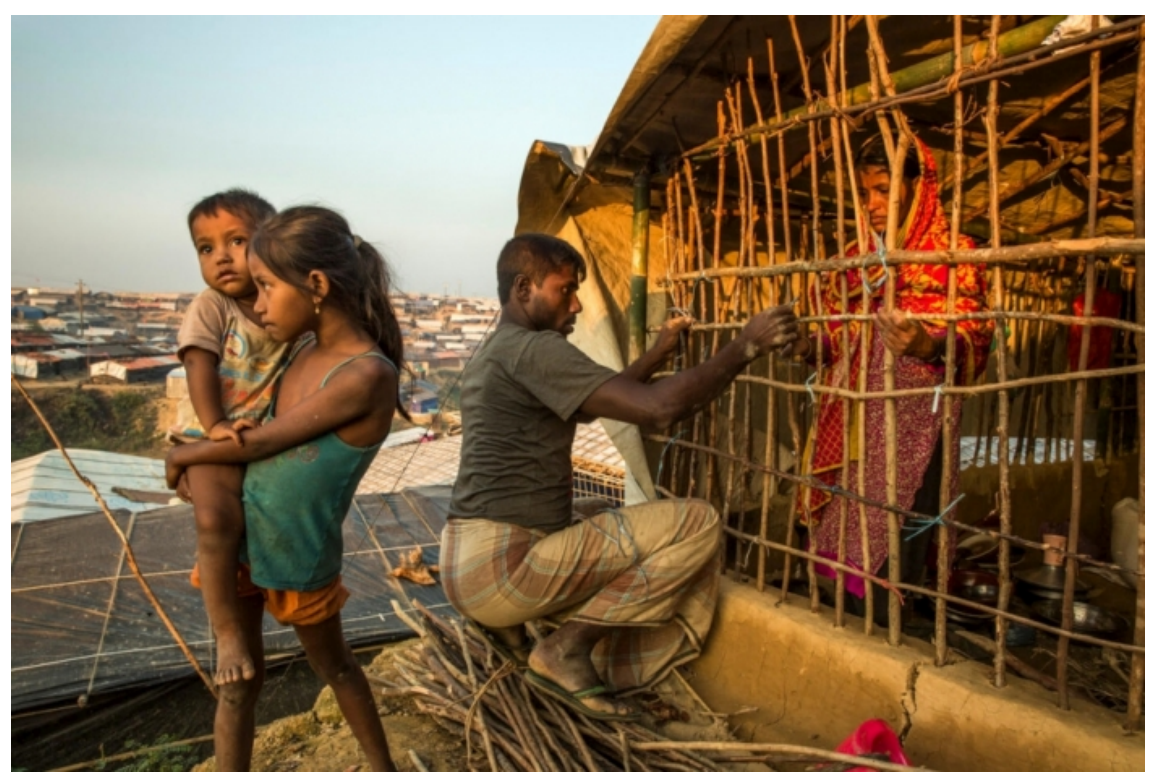

Image 3. Nur Hossen makes improvements to his family's shelter at Kutupalong refugee camp in Bangladesh, Source: (UN High Commissioner for Refugees, 2018). 
smokes in the kitchen.

- International aid agencies and local charities and local volunteers need to be working together to manage shelter related problems of the camps. Proper shelter management initiates would be challenging without the supply of clean water and sanitation.

- There is a need to provide technical support and advice regarding Shelter in different phases of upcoming crisis management, such as: preparedness, response and recovery to make sure that no household should be in lack of proper shelter during crisis especially during natural disasters. We also need to ensuring proactive practical actions and proper coordination.

- We also need to ensure the predictability and effectiveness of market-based approaches in shelter activities. We need to strengthen the linkages among glocal (both global and local) coordination of shelter management efforts during and immediate after emergency crises.

\section{Conclusion}

Bangladesh is already an over populated country, if we keep the Rohingyas here and not take steps to send them back to where they belong, the Rohingyas will become a burden to the country. And since the population will increase, unemployment problem will increase as well. Already Bangladesh is a developing nation and it has an acute problem of unemployment. Now that new migrants have arrived, they somehow need to choose a livelihood in order to live hence this will rise employment rates there will be a negative impact on economy.

Bangladesh has now become the shelter spot for the safety of hundreds of thousands of Rohingya refugees in Cox's Bazar and they are at risk during the monsoon season. IOM and the UN Migration Agency have already provided major shelter materials to help 120,000 households in camps and local communities volunteered for vital improvements to the shelters of the refugees. As there is the risk of heavy rains and cyclone winds in the camp locations so urgent action is required to support them to strengthen the shelters as due to climate change the intense floods, landslides and strong winds will be a deadly threat for thousands of Rohingya families living in the camps. By doing this we would be able to mitigate the potential damage to the shelters of the Rohingya households by ensuring access to materials and technical support to improve their existing conditions. Government, International aid agencies and local charities should work together to provide support to the Rohingya refugees help to make their shelters better.

Approximate Timeline of the Data Collection \& Paper Write-up: January 2018 to March 2018.

The Rohingya relocation in a Chor Land of Bangladesh (Bhasan Chor) has started from December 2020 and some families have relocated in that area. But there are still so many families living in the camps. This paper is relevant to the existing the conditions of the refugee camps. 


\section{Conflicts of Interest}

The authors declare no conflicts of interest regarding the publication of this paper.

\section{References}

Al Jazeera (2017). Rohingya Refugees Search for Shelter in Bangladesh. Retrieved from In Pictures: Humanitarian Crises.

https://www.aljazeera.com/indepth/inpictures/2017/09/rohingya-refugees-search-shelt er-bangladesh-170926103414078.html

Albert, E. (2018). The Rohingya Crisis. Retrieved from Council on Foreign Relations. https://www.cfr.org/backgrounder/rohingya-crisis

Beaubien, J. (2018). Monsoon Rains Could Devastate Rohingya Camps. https://www.npr.org/sections/goatsandsoda/2018/02/07/583419363/monsoon-rains-co uld-devastate-rohingya-camps

Bhattacherjee, A. (2017). Rohingya Crisis: Policy Options and Analysis. Bangladesh Institute od Peace and Security Studies. Dhaka: BIPSS.

http://bipss.org.bd/pdf/Rohingya-Policy\%20Brief.pdf

International Organization for Migration. (2018). IOM Bangladesh: Rohingya Refugee Crisis Response. External Update, 19-25 January 2018.

Martin, W. (2017). Strategic Recommendations for Shelter Upgrade in Response to the Rohingya Humanitarian Crisis. Global Shelter Cluster. Baltimore: Catholic Relief Services

UN High Commissioner for Refugees (UNHCR) (2018). Rohingya Refugees Race to Fix up Shelters as Monsoon Looms. 